\title{
Gemeentegeskiedskrywing en die ontsluiting van die geskiedenis van die Afrikaanse Kerke
}

\author{
E Brown
}

Die geskiedenis van die plaaslike gemeente is vir die Afrikaanse Kerke van primêre belang. Dit dien die selfbegrip van die afsonderlike kerke en kan help om die geskiedenis waarby hulle met mekaar betrokke is, te ontsluit. Die bewering word op teologiese en historiese gronde gemaak.

Hierdie kerke kom na vore en laat hulle verteenwoordig in soveel plaaslike gemeentes. Dit is allereers in die gemeente waar Christus, volgens die Bybels-Reformatoriese belydenis van die Afrikaanse Kerke, in sy Woord en deur sy Gees met sy kerk op pad is. Dit is in die plaaslike gemeentes waar die kerk sy geskiedenis allereers en spontaan belewe en wil laat beskrywe.

Die geskiedenis van die Afrikaanse Kerke lewer ook bewys dat die gemeentes ' $n$ bepalende en besondere invloed het. Dink maar aan Mooirivier, Lydenburg, Rustenburg, die Konsulentsgemeente van Pretoria. Die bestudering van die veelvuldige verbande, die genitiewe, van die plaaslike gemeentes bied 'n uitnemende toegang om die besondere en algemene aspekte van die Afrikaanse kerkgeskiedenis uit te klaar. Maar dan moet sy problematiek ondervang word. Laat ek dit probeer aandui met verwysing na:

1. Die motivering van gemeentegeskiedskrywing, $\mathrm{nl}$ die poging van die kerk om voortgang aan sy bediening te gee, en

2. Die veelledige betrekking wat die gemeentegeskiedenis met die Afrikaanse kerkgeskiedenis in die algemeen het.

\section{DIE MOTIVERING VAN GEMEENTEGESKIEDSKRYWING}

Aan die geskiedenis kan en wil die Bybels-Reformatoriese gelowige, en die kerk, nie ontkom nie, want sy "taak is steeds een taak in de geschiedenis"1. Buitendien glo hy en sy kerk aan die leiding en lering van die Heilige Gees in die loop van die geskiedenis.

Hierdie geloof van lidmaat en kerk kom op 'n besondere wyse navore in die plaaslike gemeente, waar die kerk direk en voortgaande betrokke is by die bediening van die Woord in die gemeenskap. Historiese gebeure, veral gedenkdatums, roep 'n "historisch besef" wakker en dring aan op "historie-onderzoek" en beskrywing. 
Die gemeente word opnuut bewus van sy taak en hy wil glo dat hy behou is om daarmee voort te gaan.

Met verwysing na die Woord en sy geskiedenis wil hy sy lidmate opwek en hom in sy bediening laat aanbeveel. Op die leiding van die Here word gewys. Maar die lering van die Heilige Gees word nie altyd histories verantwoord en verwerk nie.

Dit kom daarvan dat die geskiedenis van 'n gemeente nie sondermeer 'n aanbeveling is nie, of vanweë verskille, wat so dikwels in geskille ontaard, of vanweë sondes, wat dikwels nie na bo kom nie.

Publikasies neig dan ò om by die moeilikhede van die verlede verby te gaan òf met ' $n$ terloopse verwysing te volstaan. Omdat die verlede soms so vlak en vars is, is ' $n$ verantwoorde beoordeling inderdaad moeilik. Daar word veral en met goeie rede, gevrees dat betrokkenes onbillik behandel kan word en gemeentelede aanstoot kan neem. Baie gemeentes met 'n omstrede geskiedenis stel liewer nie 'n gedenkboek op nie. Ander voel hulle gedwonge om hulle saak te laat stel. Die eerste pogings van gemeentegeskiedskrywing is eintlik bedoel om geskille en knelpunte van die verlede te verduide$\mathrm{lik}^{2}$. Gevolglik neig hierdie genre om eensydige geskiedskrywing te pleeg. Dit kom nie tot die beoefening van kerkgeskiedenis met indringende vraagstelling wat histories en teologies uitklaar nie. Sodoende word die gemeente en die geskiedenis van die Afrikaanse Kerke ontdoen van die volle lering van die Heilige Gees en die geskiedenis in ' $n$ besondere en algemene sin.

Hierdie onverantwoordelike omgang met die geskiedenis van die gemeente sluit natuurlik aan by die kerkisme wat ons vaderlandse kerkgeskiedskrywing apologeties en polemies skeeftrek. Dié benaderingswyse het die problematiek van die vakgebied in 'n sekere sin geïdentifiseer, maar uit die oog verloor dat dit kerkhistories slegs om ' $n$ besondere kerk gaan omdat dit om die kerk van Christus gaan. Bybels-Reformatories sou die strekking en stelling van hierdie vertolking kerkhistorici algaande onvergenoegd laat. Met die aanvaarding van sy opdrag in 1960 het prof FN Hanekom na die belydenisskrifte verwys en die "verhewe taak" van die kerkhistorikus beklemtoon, nl. "om die ontstaan, lewe en ontwikkeling te ondersoek van daardie besondere gemeenskap, wat hom, hoewel in aardse kleed, laat ken het as die liggaam van Christus, waarin, deur die verkiesende genade van God, opgeneem is sy uitverkorenes uit alle volkere, om vir Hom 'n nuwe en eie volk te wees" ${ }^{3}$. Prof AD Pont het, eweneens met verwysing na die belydenis, hom met die kerkhistorikus van Stellenbosch vereenselwig. Dit bly egter nog steeds ' $n$ historiese en teologiese probleem, en uitdaging, so het hy tereg daarop gewys, om die geskiedenis van die Afrikaanse Kerke te interpreteer en te beskrywe ${ }^{4}$. 
Met ' $n$ Bybels-Reformatoriese verantwoording leen die bestudering van die geskiedenis van die plaaslike gemeente hom uitnemend om die besondere en algemene aspekte van die Afrikaanse Kerke te hervertolk. Veral vanweë die veelledige aansluiting van die gemeentegeskiedenis by die geskiedenis van die Afrikaanse Kerke.

\section{DIE VEELLEDIGE BETREKKINGE VAN DIE GEMEENTEGESKIEDENIS MET DIE AFRIKAANSE KERKGESKIEDENIS}

Elke plaaslike gemeente is anders, òf vanweë sy agtergrond en die verwerking daarvan, òf vanweë sy samestelling en identifisering, òf vanweë bepaalde faktore en 'n besondere ontwikkeling ò aksentuering, veral deur leidinggewende ampsdraers. Daarom moet dit na sy eie verlede en die besondere kenmerke daarvan tipeer en beskrywe word. Dit wat gebeur het en wat eie aan hom is, moet vraagstellend uitgeklaar word.

Daarin moet rekening gehou word met die genitiewe van die Afrikaanse gemeente. As dit gebeur, kan dit insiggewend wees by die vraagstelling aan die Afrikaanse kerkgeskiedenis. Die gemeente se geskiedenis is vervlegd, want dit is betrek by 'n bepaalde streek, eintlik ' $n$ besondere gemeenskap van ' $n$ land en sy regering. Daarnaas is dit ' $n$ gemeente van 'n besondere kerkverband, eintlik van 'n bepaalde groep van kerke wat in die geskiedenis en belydenis aansluiting vind.

Tot 'n groot mate lê die problematiek van die vakgebied in die ontrafeling van hierdie relasies. As elkeen nie behoorlik verreken word nie verloop die beskrywing misleidend. Dikwels word die aanbieding vanuit een relasie op sleeptou geneem. Dit gebeur veral as gevolg van die motivering en entoesiasme van die beoefenaars. Gewoonlik word gesê dat hulle as ' $t$ ware omgepraat is, of aanvanklik gehuiwer het om die geskiedenis op te stel. Betrokkenes en ambisieuse amateurs laat hulle egter geredelik vind om die verlede op te skrywe. Min is egter vakkundig in staat om reg aan die wetenskaplike eise te laat geskied ${ }^{5}$. Maar ook gesanksioneerde vakkundiges kan die gemeentegeskiedskrywing misbruik wanneer die interpretasie gerig is op bewysvoering.

Laat ek probeer om aan te toon hoe in die genitiewe van die gemeentegeskiedenis die geskiedenis van die Afrikaanse Kerke belig kan word.

\section{Die geskiedenis van die gemeente in sy betrekking tot die bepaalde streek}

Geskiedskrywing van 'n gemeente kan in 'n sekere sin geklassifiseer word as streekgeskiedenis. $\mathrm{Lg}$ is ' $\mathrm{n}$ dissipline wat in die resente tyd 
op sy eie reg en metodiek aandring ${ }^{6}$. In 1975 het die RGN daartoe gekom om 'n Afdeling Streeksgeskiedenis by sy Instituut vir Geskiedenisnavorsing in te stel.

Dat 'n streek die Afrikaanse Kerke beïnvloed het, is reeds in studies bewys'. Dit hang natuurlik ook saam met die besondere genitiewe van die bepaalde streek. Daar is veral gewys op die beinvloeding van voorposomstandighede, die samestelling van die samelewing, die gangbare politieke beleid en wyse van vestiging. Die vraagstelling moet egter verder deurgevoer word. Nie net op die positiewe beinvloeding nie, maar ook op die negatiewe kondisionering van die streek, en byname historiese inbeelding, moet ingevra word. Bykomende vrae moet geopper word. Byvoorbeeld, is afskeiding 'n optrede eie aan 'n streek? En, in die geval van die afskeiding van die Gereformeerde Kerk, was dit primêr teologies van aard? Het dit noodsaaklik geword bloot omdat daar 'n verwording plaasgevind het en die sogenaamde eens suiwere gereformeerde leer verder verlore gegaan het veral met die Skotse bediening? Het die Nederlandse Kerk nie reeds onderskeie teologiese skakerings gehad nie? Soos wat hy huidig hulle as rigtings akkommodeer nie? Soos wat ook in die geledere van die Ned Geref Kerk nog onderskeie standpunte voorkom nie? Met hierdie aansluitende vraagstelling wil ek nie beweer dat daar nie goeie rede was vir die kerklike vasgryp van Bybels-Reformatoriese uitgangspunte nie.

Hierdie vraagstelling m.b.t. die geskiedenis van 'n gemeente en sy streek kan sinvol wees. Want die kerkhistorikus het hier onmidellike toegang tot die kerk en sy lidmate. Hy het te make met "real people and situations in depth and detail ${ }^{\prime \prime}$. En, die godsdienstige oortuiging en sentimente was eweneens in die Afrikaanse gemeenskap basies, soos A Rogers dit uitsonder vir streekgeskiedenis in die algemeen, "for it not only united the community but it also on occasion divided it. In many ways, it was the politics of yesterday"9.

\section{Die geskiedenis van die gemeente in sy betrekking tot 'n besondere gemeenskap, die Afrikaner en sy kultuur}

As streekgeskiedenis staan die geskiedenis van 'n Afrikaanse gemeente insgelyks in verband met 'n besondere gemeenskap, wat homself in sy eie kultuur- en volksbewussyn identifiseer.

Toe die Kultuurgeskiedenis van die Afrikaner in 1947 beskrywe is, is die Afrikaanse Kerke as deelhebbers tereg opgeneem ${ }^{10}$. In die onderskeie oorsigte is geensins ingegaan op die teologiese effek van Afrikaner-wees op die onderskeie kerke nie. In die afgelope twee dekades is veral toegespits op die teologiese nagevolge van kultuurhistoriese beïnloeding wat hierdie kerke ondergaan het. Dat die 
Afrikaner se nasionalisme sy kerke uitgedaag het om in sy bediening na vore te kom en homself te laat geld, ly geen twyfel nie ${ }^{11}$. Dit verder bekend hoedat in tye toe die Afrikaners mekaar na binne gesoek het, aangedring is dat die kerke mekaar na binne sal vind ${ }^{12}$. Toe sy voortbestaan bedreig is in die Tweede Vryheidsoorlog het talle Afrikanerseuns hulle aangemeld vir die bedieníng, veral as sendelinge ${ }^{13}$. Maar in resente studies word nou gesê dat die Afrikaners se kerk kultuur-histories op sleeptou geneem is; in hulle sendingbeleid ${ }^{14}$; in hulle politieke aspirasi ${ }^{15}$. In hierdie studies word van hipotese-interpretasie gebruik gemaak, bv dié van Max Weber en RH Tawney in verband met Calvyn en die kapitalisme, Emerich Francis in verband met rassisme, en Michael Walzer in verband met burgerlike godsdiens. Met die kontemporêre aandrang op 'n Christendom "Jenseits burgeliche Religion"16 het dit gebiedend noodsaaklik geword om met onderskeiding die negatiewe en positiewe, die wedersydse beïnvloeding van Afrikaanse Kerke en Afrikanerdom kerkhistories na te gaan. Daarin het TN Hanekom reeds in die vyftigerjare aandag gegee toe hy "Kerk en Volk" as "die verhouding tussen Afrikaanse lewenskringe" tipeer het ${ }^{17}$. Bestudering van hierdie probleem kan geen beter kennismateriaal kry as dié van die plaaslike gemeente nie. 'n Onlangse proefskrif het in hierdie verband daarop gewys hoe die kultuurbegrip van die Ned Geref Kerk ' $n$ beslissende faktor was waarom die twee Afrikaanse gemeentes in Argentinië vir so lank nie aansluiting bymekaar kon realiseer nie ${ }^{18}$.

In so ' $n$ studie kan eweneens antwoord kom op die vraag in hoeverre ondersteuning van en voorkeure aan, politieke sentimente in Afrikaner geledere die onderskeie kerke beïnvloed het? Veral bestudering van gemeentes waarin spanning in hierdie opsig belewe is en skeuring plaasgevind het, sal insiggewend wees.

\section{Die geskiedenis van die gemeente in sy betrekking tot ' $n$ besondere Afrikaanse kerk}

Allereers is die gemeente se geskiedenis ineengeskakel met 'n geïnstitueerde kerk met ' $n$ naam van sy eie. Dit is in 'n streek een van die gemeentes van ' $n$ kerk wat op ' $n$ besondere historiese en kerkregtelike wyse onder Afrikaners na vore gekom het. Hierdie verband word amptelik gereël, maar ook belewe en geïdealiseer deur lidmate. Sodoende onderskei die een kerk homself van die ander twee Afrikaanse kerke met 'n historiese en teologiese selfbegrip en inbeelding van sy eie, ten spyte van die feit dat al drie dieselfde belydenisskrifte onderskrywe ${ }^{19}$. Oor hierdie selfbegrip is daar in die Ned Geref Kerk van tyd tot tyd verduideliking aangevra - en nie eenstemmigheid bereik nie ${ }^{20}$. 
Die gemeentegeskiedskrywing van hierdie onderskeie kerke is oor die algemeen verskillend waargeneem. In die Ned Herv en Geref Kerke is dit gewoonlik van buite deur 'n kundige lidmaat van die kerk beskrywe. Hierdie twee Kerke het baie meer erns gemaak met die historiese ondersoek. Sekerlik omdat hulle sodanige beskrywing belangrik vir die algemene of breëre kerk beskou het. Die gevaar is egter dat die geskiedenis van die breëre kerk in dié van die gemeente geprojekteer is, dat die gangbare interpretasie van die geskiedenis van die kerkverband sonder meer vanuit die geskiedenis van die gemeente geillustreer en geaksentueer is. So word aanvaar dat die een by die ander gelykskakel. Die algemene geskiedenis van die kerkverband kan egter nie eenvoudig uit die geskiedenis van sy onderskeie gemeentes afgelees word nie. Die totale geskiedenis van sy gemeentes is nie gelyk aan die totale geskiedenis van die algemene kerk of kerkverband nie. Maar nou moet aan die ander kant insgelyks nie mistasting wees nie. Die Ned Geref Kerk het geneig om die gemeentegeskiedenis op sy eie te laat figureer, terwyl baie geskrifte nie veel meer is nie as 'n plaaslike vertoon. Gedenkboeke het ' $n$ bedryf geword. Die gemeente kan nie wag om sy verlede te laat "opstel", of "saamstel", nie. Historiese verbandstelling en verwerking bly dikwels in die slag. Die breëre kerk kom slegs soms daarby, as dit gebeur. Ook met betrekking tot hierdie genitief van die gemeentegeskiedenis moet die vraagstelling van twee kante plaasvind. Daar moet in die eerste instansie vasgestel word wat die selfbegrip van die gemeente in plaaslike verband is. En, gelyktydig, hoedat dit met dié van die bepaalde kerk verband hou, d.w.s. ooreenstem en verskil. Vir hierdie ondersoek moet die kerkraad en predikant bereid wees. Dan sal die gemeente homself Bybels-Reformatories aanbeveel in sy voortgesette bediening van 'n gemeenskap. Want dan kom dit deur dat dit om 'n bepaalde kerk en ' $n$ besondere gemeente gaan slegs omdat dit bo alles om die kerk van Christus gaan.

As hierdie ondervraging tussen gemeente en kerk plaasvind, is ek oortuig sal die onderlinge verband tussen die drie Afrikaanse Kerke sterker uitkom. 'n Verband wat die lidmate nie prysgee nie. Dink maar daaraan hoe hulle van een kerk, of liewer 'n gemeente van een kerk, oorskakel na'n ander.

\section{Die geskiedenis van die gemeente en sy betrekking tot die ander Afrikaanse Kerke}

Op die plaaslike vlak is hierdie verhouding bepaald anders as wat dit amptelik hanteer en kerkhistories gestel word. Sekerlik omdat lidmate van die onderskeie kerke so aangewese is op mekaar, saamwoon en saam werk, saam optree en organiseer, saam speel en 
ontspan, saam instaan vir hulle identiteite, saam Christen moet wees. By hulle is die aansluiting by wat bind. By amptelike onderhandelinge word op dit wat onderskei, gekonsentreer. In die geskiedenis van die gemeente, wat gewoonlik onder toesig van die kerkraad uitgegee word, word nog te bolangs na hierdie kontak verwys. Daar word volstaan met boodskappe of met oorsigte wat van ander kerke aangebied word. Die betrekking word nie uitgepluis nie.

Ek wil tot ' $n$ besluit kom. Vooraf wil ek egter onder hierdie hofie 'n mening lig. Amptelik en in die beoefening van die kerkgeskiedenis is ons nog te veel vasgevang deur geskiedsbeelde, of inbeeldings, wat ons teenoor mekaar hou. Daar is vir my kerkhistoriese aanduidings vir die volgende siening, en korrektief, van ons denke oor mekaar. Dat die "Neerlandse kerk", wat uit die Hervorming geërf en in Suid-Afrika oorgeplant is, nie so eenstemmig na binne was as wat ons dit vanuit ons onderskeie Afrikaanse Kerke indink nie. Immers, studies bevestig dit dat daar skakering van die begin af was. In gemeentes en tussen gemeentes aan die Kaap kom bewyse hiervan voor. Hierdie verskille het met verloop van tyd in die SuidAfrikaanse konteks, veral as gevolg van nuwe opnames, by name die bediening van die Skotse predikante en liberale oriënterings, wat veral van Nederland oorgedra is, 'n identiteitskrisis laat ontstaan.

Verskille het geskille geword en uitgeloop op onderskeie kerke, wat hulle in vergelyk met die Moederland gestel het. Die een kerk het teenoor die ander kerk te staan gekom. In die kerkgeskiedskrywing is 'n saak vir elkeen se afsonderlike bestaan uitgemaak en die Bybels-reformatoriese visie op die kerk laat vervaag. Gevolglik is die beoordeling van die geïstitueerde kerke in terme van die kerk van Christus nagelaat in kerkisties-gemotiveerde geskiedskrywing wat geskille vooropstel. In voortgaande amptelike onderhoude kom ons met mekaar nie verder nie omdat voortgaande gestuit word op verskille. En, verskille is daar ook om mee rekening te hou.

As die ontwikkeling van verskillende geïnstitueerde kerke vanuit die plaaslike gemeentes plaasgevind het, word uit die oog verloor dat dit weer die plaaslike gemeentes is wat dit beredder. En, voortgaan om dit te doen, daar waar die kerk met sy lidmate daagliks by sy taak betrokke is. En, tot ' $n$ vergelyk kom om met mekaar te verskil, ter wille van die verband waarin hulle betrokke is en die bediening waarin hulle staan.

Of ons daarom moet verenig, verskil ons. 'n Historikus weet maar al te goed dat, soos GM Pellissier, een van die hoogleraars in die teologie in hierdie belangrike universiteit, dit gestel het, "oor die geskiedenis kan 'n mens nie spring nie." Maar met die geskiedenis mag die Bybels-Reformatoriese kerk, lidmaat en kerkhistorikus nie sonder meer verlief neem nie. 
Is een kerk met onderlinge verskille moontlik en wenslik? Ek behoort aan so ' $n$ kerk. Dit is sekerlik die rede waarom so baie uit sy geledere op vereniging aandring. Soms met 'n naïewe appèl, en sonder om te wil erken dat ook hierdie Kerk se geskiedenis hom nie sonder meer aanbeveel nie.

Ten slotte: een ding is seker, saam en elkeen afsonderlik moet ons die geskiedenis van die Afrikaanse Kerke hervertolk en bedien. Noudat ooreengekom is dat dit in die sin van ons Bybels-Reformatoriese geloof moet gebeur. Vanuit die geskiedenis en in die bediening van die plaaslike gemeente kan hierdie uitdaging 'n sinvolle gevolg hê. Nêrens kry die kerkhistorikus 'n beter weergawe van die Afrikaanse kerk en kerke nie. In plaaslike verband is gemeentes van dié kerke betrokke by die taak, wat hulle uit die Skrif aflees en die besondere kerk vir hulle help waarneem. In hierdie bediening is hulle betrokke, omdat hulle in die streek die kerk van Christus wil laat geld en daarom hulle met 'n betrokke gemeenskap identifiseer. Op geen ander wyse kry die kerkhistorikus meer direkte toegang tot die kerk en kerke wat hy wil bestudeer nie.

In 'n stad wat 125 jaar oud is, en van die begin af begelei is deur die Afrikaanse Kerke, het ons alma mater hierdie studie help moontlik maak. Vir 50 jaar beveel hy homself al as universiteit aan: ad destinatum persequor.

Vir 50 jaar was Afdeling A van die Teologiese Fakulteit daarby. As oud-student van Afdeling B, wat daarnaas bygekom het, wil ek die bede uitspreek dat die voortgesette bestudering van die geskiedenis van hierdie kerke hulle bediening sal aanbeveel: DEO GLORIA.

\section{Bibliografie}

1. KJ Popma: Calvinistische Geschiedenisbeschouwing. Franeker, 1945, 92.

2. E Brown: Gemeente-geskiedskrywing. Durban-Pretoria, 1971, 82.

3. Ons Vaderlandse Kerkgeskiedskrywing. sp (1960), 3.

4. "Enkele opmerkings oor objektiewe kerkgeskiedskrywing," Hervormde Teologiese Studies, 18de Jg 1962-1963, 146-153.

5. Cf HPR Finberg en VHT Skipp: Local history, objective and pursuit. 44; PL Scholtz: Streekgeskiedenis - 'n fassinerende mikrckosmos, Intreerede, UWK series A no. 26 1978, 18-19; WG Hoskins: Local history in England, 4-5; D. Iredale: Local history, research and writing, 9.

6. Cf Scholtz: op cit, passim.

7. Eg B Spoelstra: Die "Doppers" in Suid-Afrika, 1760-1899. Kaapstad, ens. 1963, Brown: op cit., $165 \mathrm{ff}$.

8. R Douch: Local history and the teacher. London, 1972, 7.

9. Approaches to Local history, London, $1977^{2}, 126$.

10. Onder redaksie van $C M$ van der Heever en $P$ de V Pienaar, 3 dele. Kaapstad, ens., 1947. Artikels deur GBA Gerdener namens die Ned Geref Kerk (288ff), SP Engelbrecht namens die Ned Herv Kerk (224ff) en S du Toit namens die Geref Kerk (249ff).

11. Cf $P$ Meiring in Church and Nationalism in South Africa, Geredigeer deur Theo Sunderneier. Johannesburg, 1975. 
12. Cf CS Kotze: Die Nederduitse Gereformeerde Kerk en die Ekumene, 1780-1910. Ongep DTh proefskrif, US, $1978,183 \mathrm{ff}$.

13. Cf JW Kok: Sonderinge vrug, die invloed van die Tweede Vryheidsoorlog op die sendingaksie van die NG Kerk in SA Pretoria, 1971.

14. Cf O Nederberger: Kirche-Mission-Rasse, die Missionsanffassing der NiederländeschReformierten Kirchen von Süd-Afrika, Schöneck-Beckeuried, 1958. G Beckers: Religiöse Faktoneirün der Entwickling den Südafrikanischen Rassenfrage. München, 1969.

15. Cf WS de Klerk: The Puritans in South Africa. London, 1975, T Dunban Moodi: The Rise of Afrikanerdom, power, apartheid and the Afrikaner and Religion. Berkely-London, 1975.

16. JB Metz: München-Mainz, 1980. In die series Forum Politische Teologie, nr 1

17. Kaapstad-Pretoria, sd, passim, veral $95 \mathrm{ff}$.

18. FRP de Bruyn: Die stryd om kerklike eenheid onder die Afrikaners in Argentinië, 1915-1954. Ongepubliseerde Th D Proefskrif, PU vir CHO., 1979.

19. Cf die polemiek tussen prof SP Engelbrecht en JV Coetzee, in eersgenoemde se geskrifte, Neo-Calvinisme, ontwikkeling en afwyking. Pretoria - Kaapstad 1945, en laasgenoemde $s^{\prime} n$, Neo-Calvinisme, verbastering of regte ontwikkeling. Potchefstroom, sd.

20. Cf eersgenoemde "Bekommerd": Christus die Deur, die twee rigtings van die Calvinisme, Kaapstad, 1936 en DG Malan, A Lategan en EE van Rooyen: Christus en Calvinisme, die ware toedrag van sake teenoor "Bekommerd" toegelig. Stellenbosch, 1936. 